\title{
A Preliminary Experiment of Non-Catalytic Transesterification: Thermal Analysis of Palm Oil and Biodiesel at Different Ratio
}

\author{
Mei Yin Ong ${ }^{1}$, Bello Salman ${ }^{2}$, Nor-Insyirah $\mathrm{SAL}^{3}$, Refal Hussein ${ }^{4}$, Saifuddin Nomanbhay ${ }^{5 *}$ \\ Institute of Sustainable Eneryf (ISE), Universiti Tenaga Nasional (UNITEN), Jalan IKRAM-UNITEN, \\ 43000, Kajang, Selangor, Malaysia. \\ *Corresponding author E-mail: saifuddin@uniten.edu.my
}

\begin{abstract}
Currently, the biodiesel production technology is moving toward the trend of non-catalytic reaction under subcritical condition as the conventional non-catalytic transesterification requires high energy input and high production cost. Hence, non-catalytic biodiesel production under subcritical condition using microwave energy is proposed. Before that, thermogravimetric analysis (TGA) was conducted to characterize the biodiesel feedstock and determine the suitable experimental temperature range for the proposed method. Besides, the thermal behavior of the palm oil and biodiesel at different stages of reaction was also investigated. The results showed that the palm oil and biodiesel were started to degrade from $335^{\circ} \mathrm{C}$ and $160^{\circ} \mathrm{C}$ respectively. However, the degradation point of palm oil was higher than the supercritical temperature of DMC. So, external energy is needed to bring down the operating condition, such as microwave energy as it has potential to reduce the activation energy. To further eliminate the problem of biodiesel thermal degradation during the transesterification process, the suggested experimental temperature range is within $80^{\circ} \mathrm{C}$ to $180^{\circ} \mathrm{C}$, which is from the temperature lower than the boiling point of DMC $\left(<90^{\circ} \mathrm{C}\right)$ to the temperature slightly higher than the biodiesel thermal degradation point. Furthermore, DSC result indicated that palm oil requires $518.35 \mathrm{~kJ} / \mathrm{mol}$ to decompose.
\end{abstract}

Keywords: Differential scanning calorimetry (DSC); Microwave-assisted reaction; Non-catalytic transesterification; Palm oil; Thermogravimetric analysis (TGA)

\section{Introduction}

Climate change, including temperature risings, erratic weather and glaciers melting, has been witnessed in the last 30 years due to the increasing of greenhouse gas (GHG) emissions. Studies shown that GHG emission is highly dependent on the burning of fossil fuels, and so, exploring of alternative renewable energies is necessary in order to meet the global warming targets [1]. Besides, the amount of fossil fuels is limited on the Earth and their formation took hundreds of millions years. Nevertheless, $80 \%$ of the current global energy requirements are dependent on them and as a results, large percentage of total amount of fossil fuels formed has been exploited in just a few recent centuries.

In order to scale down the dependency on fossil fuels, biodiesel has been introduced as the alternative renewable liquid fuel. Biodiesel is a biodegradable and non-toxic fuel that produce less harmful gaseous emission into the environment. It has the potential to replace the petroleum-based diesel as both of them consist of similar fuel properties [2]. Since most of the industrial areas and transportation require liquid fuel to function the machinery and engines, hence, biodiesel should be more emphasized. Transesterification is one of the widely-used biodiesel production method. Nevertheless, the oil-to-biodiesel conversion technology exist inefficiencies, which results in high production cost [3].

Hence, numerous researches have been conducted to enhance the biodiesel production process [4-7]. Non-catalytic transesterification under subcritical condition is the current trend as it shows the possibility to produce biodiesel in a greener and less-complicated way [8]. This is because it consists of high adaptability to the cheaper feedstock, which usually consists of high free fatty acid (FFA) and water content. Moreover, this technology does not require complicated pre-treatment and downstream process.

To the best of found knowledge, the implementation of microwave technology into non-catalytic transesterification under subcritical condition has never been explored. Microwave processing is one of the well-known green technology that able to enhance the chemical reactions and produce cleaner product. In addition, microwave-assisted reaction allowed low energy consumption and process intensification as the results of selective heating and reaction acceleration. These unique phenomenon observed could be explicated by the thermal and non-thermal microwave effects $[8$, 9]. Moreover, to further increase the economic viability of biodiesel production, dimethyl carbonate (DMC) has been suggested to replace the conventional methanol as DMC is a green solvent with better miscibility properties, and the DMC-mediated transesterification process will produce higher value-added by-products, glycerol carbonate, instead of the waste glycerol.

Before conducting the proposed non-catalytic biodiesel production under subcritical condition using microwave-assisted reaction, thermogravimetric analysis (TGA) should be conducted to identify and characterize the biodiesel feedstock. Besides giving fast assessment, this thermal analytical method requires only a small amount of sample size. Thus, it is a preferred and accepted method to determine the thermal behaviour or properties of a material. Moreover, TGA is important to find the suitable experimental temperature range for a non-catalytic transesterification reaction as no catalyst is used during the reaction [10]. 
In this study, the biodiesel feedstock chosen is palm oil. Malaysia is the second largest world palm oil producer, and hence, palm oil will be a good suggestion for studying the biodiesel production technology in Malaysia. In short, this paper presents the results of thermogravimetric analysis (TGA) for palm oil. Besides, the TGA of palm oil and biodiesel with different percentages were also performed to study the thermal behavior of the palm oil and biodiesel at different stages during the reaction process. Moreover, another thermal analysis, differential scanning calorimetry (DSC) was conducted to determine the physicochemical transformations happening when heating up. It is a useful tool in fats and oils areas, especially in quality control and development of new fat and oil product.

\section{Methodology}

\subsection{Materials}

The palm oil and biodiesel used in this project were obtained from the local supplier.

\subsection{TGA of Palm Oil and Biodiesel Blend at Different Ratio}

Firstly, the fresh palm oil and biodiesel was mixed at different ratio (v/v \%). Then, the thermogravimetric analysis (TGA) of the samples with different percentages were performed with a Mettler Toledo TGA/SDTA851 ${ }^{\mathrm{e}}$. In the TGA experiment, appropriate amount of sample was placed into a $100 \mu \mathrm{l}$ alumina crucible and then put on a crucible holder inside the furnace. Next, the sample was heated from $30^{\circ} \mathrm{C}$ to $700{ }^{\circ} \mathrm{C}$ at a heating rate of $15^{\circ} \mathrm{C} / \mathrm{min}$. The sample mass was measured by the thermobalance in the instrument throughout the experiments. For all experiments, nitrogen, $\mathrm{N}_{2}$, was used as an inert carrier gas with a flow rate of $100 \mathrm{ml} / \mathrm{min}$. Besides, the TGA tests were performed in triplicates to ensure reproducibility.

\subsection{DSC of Palm Oil}

The DSC experiments of the fresh palm oil, however was performed with a Mettler Toledo DSC $823^{\mathrm{e}}$. The sample was firstly placed into a $40 \mu \mathrm{l}$ aluminium crucible and weighted with a digital balance before putting it into the equipment. Then, the heat capacity was tracked as changes in the heat flow to heat the sample from $25^{\circ} \mathrm{C}$ to $600^{\circ} \mathrm{C}$ at a heating rate of $15^{\circ} \mathrm{C} / \mathrm{min}$. Nitrogen, $\mathrm{N}_{2}$ was used as an inert carrier gas with a flow rate of $100 \mathrm{ml} / \mathrm{min}$ and the tests were performed in triplicates to ensure reproducibility.

\section{Results and Discussions}

\subsection{TGA of Palm Oil and Biodiesel Blend at Different Ratio}

The thermogravimetric data obtained in this experiment were expressed graphically as TG curve (see Figure 1). In order to differentiate the thermal decomposition effectively and clearly identify the individual mass change steps, the differential thermogram (DTG) was plotted and shown in in Figure 2. The error bar was eliminated in the thermogram since negligible experimental deviations were observed.

For the ease of comparison, the TGA result of palm oil was displayed as $0 \%$ biodiesel in Figure 1. Based on the results, the thermal degradation of palm oil and pure biodiesel happened in a single step reaction [11]. Nevertheless, the biodiesel at $20 \%$ to $80 \%$ involve two step decomposition, similar with the result reported by Roschat [12]. The onset temperature, $\mathrm{T}_{\text {on }}$ of every samples were determined by intercepting the tangent line of the inflection point with the extrapolated horizontal baseline at $1 \%$ degradation. Then, the values were recorded in Table 1 . Note that the actual degradation is always initialized at the temperature below $\mathrm{T}_{\text {on }}[13]$. For example, the palm oil was thermally stable up to $\sim 335^{\circ} \mathrm{C}$ and the pure biodiesel started to degrade at $\sim 160^{\circ} \mathrm{C}$. However, this temperature value is less reliable compared to the $T_{\text {on }}$ in describing as the initial thermal decomposition temperature.

TG curve at different biodiesel percentage

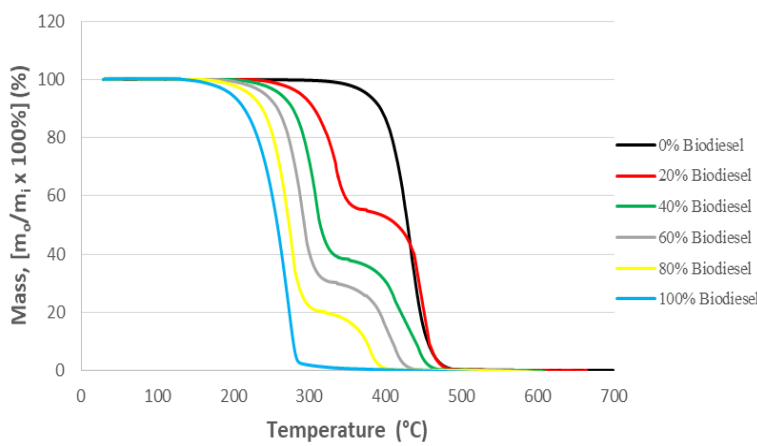

Fig. 1: TG curve of palm oil and biodiesel at different blend ratio

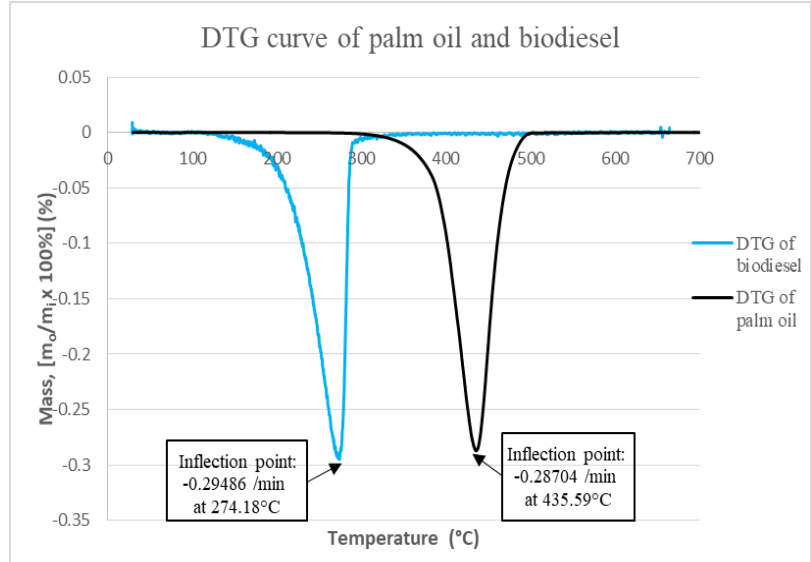

Fig. 2: DTG curve of palm oil and biodiesel

Table 1: Summary of the TGA results

\begin{tabular}{|c|c|c|}
\hline \multirow{2}{*}{ Samples } & \multicolumn{2}{|c|}{ Onset Temperature, $\mathrm{T}_{\text {on }}\left({ }^{\circ} \mathrm{C}\right)$} \\
\cline { 2 - 3 } & Methyl Ester (Biodiesel) & Palm Oil \\
\hline $0 \%$ biodiesel (palm oil) & - & 401.63 \\
\hline $20 \%$ biodiesel & 320.81 & 425.75 \\
\hline $40 \%$ biodiesel & 291.16 & 403.55 \\
\hline $60 \%$ biodiesel & 271.68 & 383.97 \\
\hline $80 \%$ biodiesel & 253.00 & 364.78 \\
\hline $100 \%$ biodiesel & 236.39 & - \\
\hline
\end{tabular}

Palm oil is made up of triglycerides and the main component of the triglyceride is fatty acids. At $\sim 335^{\circ} \mathrm{C}$, the mass decay observed can be explained by the direct bond dissociation of these fatty acids. The boiling point of the palm oil cannot be determined in this case as the direct bond dissociation of fatty acids is predominantly occurred, rather than the evaporation of triglycerides. The single step thermal decomposition of pure biodiesel, however, can be explained by the mass loss of methyl ester compounds. Hence, the TGA results of sample with $20 \%$ to $80 \%$ biodiesel are reasonable as they are the combination of pure biodiesel and palm oil and so, involve two-step decomposition reaction. These results clearly show the thermal behaviour of the possible product in this study at different stages during the transesterification process. Besides, it can be observed that the thermal stability of the sample decreased as the biodiesel percentage increased. This might be due to the bond dissociation energy requirement for biodiesel (methyl ester) is lower compared to palm oil. Thus, as the biodiesel percentage increases, the initial thermal decomposition temperature decrease. It is believed that the direct bond dissociation of triglyceride is important for a non-catalytic process, as the transesterification 
process is normally initiated by the bond dissociation of fatty acids before entering the substitution stage of two reagents $[14,15]$. In other words, the transesterification process is achievable without the presence of catalysts if conventionally heat up the palm oil to $\sim 400^{\circ} \mathrm{C}$. Besides, the reaction rate increase as the temperature increase, based on Arrhenius Equation. Theoretically, the temperature should as high as possible to overcome the activation energy more easily and at the same time, reduce the reaction time. However, it is advised that the temperature should not beyond the maximum degradation temperature of palm oil as it is not suitable to produce high biodiesel yield [16]. Jung et al. [17] studied the thermally-induced non-catalytic transesterification for biodiesel production from coconut oil with the presence of biochar as porous media. In their study, the yields of fatty acid methyl esters (FAMEs) and fatty acid ethyl esters (FAEEs) were $71 \%$ and $87 \%$ and were obtained at $365^{\circ} \mathrm{C}$ and $380^{\circ} \mathrm{C}$ respectively, which was lower than the inflection point of the coconut oil in their TGA experiment. Moreover, Figure 2 shows that the inflection point of palm oil and pure biodiesel located at $435.59^{\circ} \mathrm{C}$ and $274.18^{\circ} \mathrm{C}$ with a maximum degradation rate of $0.2804 / \mathrm{min}$ and $0.29486 / \mathrm{min}$ correspondingly. After the decomposition step, the flattening curves indicates that there is no further conversion occurred as the temperature increased.

In short, the temperature range used to investigate the optimal condition for the non-catalytic biodiesel production should lower than the thermal degradation temperature of palm oil, $\sim 400^{\circ} \mathrm{C}$. To avoid any thermal decomposition of the biodiesel formed during the biodiesel production, the reaction temperature should be further decreased, lower than the onset temperature of biodiesel. The proposed transesterification method involves the implementation of microwave heating to replace the conventional heating. Some researches show that the microwave energy has the ability to bring down the activation energy and so, it is hypothesized that the non-catalytic transesterification can occur at a lower temperature [18]. Besides, it is also interesting to study the reaction process at the temperature below the boiling point of $\mathrm{DMC}\left(<90^{\circ} \mathrm{C}\right)$. Hence, the suggested experimental temperature for the non-catalytic transesterification under subcritical condition is in the range of $80^{\circ} \mathrm{C}$ to $180^{\circ} \mathrm{C}$, which involves the temperature lower than the boiling point of DMC to the temperature slightly higher than the starting point of biodiesel thermal degradation $\left(160^{\circ} \mathrm{C}\right)$.

\subsection{DSC of Palm Oil}

The purpose of conducting DSC is to study the physical and chemical transitions happening in the sample. Besides plotting the thermogram, the DSC test reports are also summarized in Table 2. Based on Figure 3, there was only one endothermic reaction. It can be noticed that the DSC endothermic peak temperature for palm oil $\left(430.41^{\circ} \mathrm{C}\right)$ is almost similar with the TGA decomposition temperature $435.59^{\circ} \mathrm{C}$. The percentage difference for both analysis was less than $1 \%$ and hence, it can be concluded that this endothermic event was the thermal decomposition of the palm oil observed in TG and DTG curves in the previous session (refer to Figure and Figure). By integrating the area under the DSC curve at the respective peak, the enthalpy for the palm oil, which indicates indicates the energy required to decompose the sample, was calculated.

Table 2: Summary of the DSC results

\begin{tabular}{|c|c|c|}
\hline & acteristic & Palm Oil \\
\hline \multicolumn{2}{|c|}{ Onset Temperature $\left({ }^{\circ} \mathrm{C}\right)$} & 424.59 \\
\hline \multicolumn{2}{|c|}{ Offset Temperature $\left({ }^{\circ} \mathrm{C}\right)$} & 501.99 \\
\hline \multirow[t]{2}{*}{ Peak } & Temperature $\left({ }^{\circ} \mathrm{C}\right)$ & 430.41 \\
\hline & Heat flow $(\mathrm{mW})$ & 88.63 \\
\hline \multicolumn{2}{|c|}{ Enthalpy $(\mathrm{J} / \mathrm{g}$ or $\mathrm{kJ} / \mathrm{mol})$} & 611.77 or 518.35 \\
\hline
\end{tabular}

\section{References}

[1] Gerssen-Gondelach, S. J., Saygin, D., Wicke, B., Patel, M. K., \& Faaij, A. P. C., (2014), Competing uses of biomass: Assessment and comparison of the performance of bio-based heat, power, fuels and materials, Renewable and Sustainable Energy Reviews, 40, 964-998. doi:10.1016/j.rser.2014.07.197

[2] Gude, V., Patil, P., Martinez-Guerra, E., Deng, S., \& Nirmalakhandan, N., (2013), Microwave energy potential for biodiesel production,Sustainable Chemical Processes, 1(1), 5. doi:10.1186/2043-7129-1-5

[3] Lim, S., \& Teong, L. K., (2010), Recent trends, opportunities and 
challenges of biodiesel in Malaysia: An overview,Renewable and Sustainable Energy Reviews, 14(3), 938-954. doi:10.1016/J.RSER.2009.10.027

[4] Kaur, M., Malhotra, R., \& Ali, A., (2018), Tungsten supported $\mathrm{Ti} / \mathrm{SiO} 2$ nanoflowers as reusable heterogeneous catalyst for biodiesel production,Renewable Energy, 116, 109-119. doi:10.1016/J.RENENE.2017.09.065

[5] Srivastava, G., Paul, A. K., \& Goud, V. V., (2018), Optimization of non-catalytic transesterification of microalgae oil to biodiesel under supercritical methanol condition,Energy Conversion and Management, $156, \quad 269-278$. doi:10.1016/J.ENCONMAN.2017.10.093

[6] Zullaikah, S., Rahkadima, Y. T., \& Ju, Y.-H., (2017), A non-catalytic in situ process to produce biodiesel from a rice milling by-product using a subcritical water-methanol mixture, Renewable Energy, 111, 764-770. doi:10.1016/J.RENENE.2017.04.040

[7] Gohain, M., Devi, A., \& Deka, D., (2017), Musa balbisiana Colla peel as highly effective renewable heterogeneous base catalyst for biodiesel production,Industrial Crops and Products, 109, 8-18. doi:10.1016/J.INDCROP.2017.08.006

[8] Nomanbhay, S., \& Ong, M. Y., (2017), A Review of Microwave-Assisted Reactions for $\quad$ Biodiesel Production, Bioengineering, 4(2), 57

[9] Gedye, R., Smith, F., Westaway, K., Ali, H., Baldisera, L., Laberge, L., \& Rousell, J., (1986), The use of microwave ovens for rapid organic synthesis,Tetrahedron Letters, 27(3), 279-282. doi:10.1016/S0040-4039(00)83996-9

[10] Kwon, E. E., Yi, H., Park, J., \& Seo, J., (2012), Non-catalytic heterogeneous biodiesel production via a continuous flow system,Bioresource Technology, 114, 370-374. doi:10.1016/J.BIORTECH.2012.03.110

[11] Dwivedi, G., \& Sharma, M. P., (2016), Experimental investigation on thermal stability of Pongamia Biodiesel by thermogravimetric analysis,Egyptian Journal of Petroleum, 25(1), 33-38. doi:10.1016/J.EJPE.2015.06.008

[12] Roschat, W., (2015), Synthesis of Biodiesel and Glycerol Carbonate using Heterogeneous Catalysts. Suranaree University of Technology.

[13] Maton, C., De Vos, N., \& Stevens, C. V., (2013), Ionic liquid thermal stabilities: decomposition mechanisms and analysis tools, Chemical Society Reviews, 42(13), 5963. doi: $10.1039 / \mathrm{c} 3 \mathrm{cs} 60071 \mathrm{~h}$

[14] Silva, C., Weschenfelder, T. A., Rovani, S., Corazza, F. C., M. L. Corazza, †, Dariva, C., \& Vladimir Oliveira, J., (2007), Continuous Production of Fatty Acid Ethyl Esters from Soybean Oil in Compressed Ethanol,Ind. Eng. Chem. Res., 46(16), 5304-5309. doi:10.1021/IE070310R

[15] Kwon, E. E., Kim, S., Jeon, Y. J., \& Yi, H., (2012), Biodiese Production from Sewage Sludge: New Paradigm for Mining Energy from Municipal Hazardous Material,Environmental Science \& Technology, 46(18), 10222-10228. doi:10.1021/es3019435

[16] Tapaswy Muppaneni, Harvind K.Reddy, Sundaravadivelnathan Ponnusamy, Prafulla D.Patil, Yingqiang Sun, Peter Dailey, \& Shuguang Deng, (2013), Optimization of biodiesel production from palm oil under supercritical ethanol conditions using hexane as co-solvent: A response surface methodology approach,Fuel, 107, 633-640. doi:10.1016/J.FUEL.2012.11.046

[17] Jung, J.-M., Lee, J., Choi, D., Oh, J.-I., Lee, S.-R., Kim, J.-K., \& Kwon, E. E., (2017), Biochar as porous media for thermally-induced non-catalytic transesterification to synthesize fatty acid ethyl esters from coconut oil,Energy Conversion and Management, 145 308-313. doi:10.1016/j.enconman.2017.05.009

[18] Fukushima, J., Kashimura, K., Takayama, S., Sato, M., Sano, S., Hayashi, Y., \& Takizawa, H., (2013), In-situ kinetic study on non-thermal reduction reaction of $\mathrm{CuO}$ during microwave heating,Materials Letters, 91, 252-254. doi:10.1016/j.matlet.2012.09.114 